\title{
lompuler-Aided]esjgn"
}

\section{D Mass Customization Toolkits Design, Part I: Survey and an Evaluation Model}

\author{
Huiwen Zhao[0000-0002-5430-0258 $]^{1}$, Leigh McLoughlin[0000-0002-7566-3568] $]^{2}$, Valery Adzhiev[0000- \\ 0002-8447-7089] , Alexander Pasko[0000-0002-4785-7066] ${ }^{4}$ \\ ${ }^{1}$ Bournemouth University, hzhao@bournemouth.ac.uk \\ 2 Bournemouth University, lmcloughlin@bournemouth.ac.uk \\ ${ }^{3}$ Bournemouth University, vadzhiev@bournemouth.ac.uk \\ ${ }^{4}$ Skolkovo Institute of Science and Technology, Bournemouth University, \\ apasko@bournemouth.ac.uk
}

\begin{abstract}
Mass customization (MC) allows consumers to design their own products or services through online MC toolkits. The application of geometric modeling through modern web-browsers allows for the presentation of a virtual 3D product, resulting in a number of commercial 3D MC sites. To gain a deeper understanding of the toolkits that drive these sites, this article provides a comprehensive investigation into web-based toolkit design. Based on this review, an evaluation model for 3D MC toolkits is proposed that considers four aspects: Individual Differences, Solution Space, Interaction Design and Enabling Technologies. This leads to a follow-up article that applies the 3D toolkit evaluation model to assess commercial 3D toolkits which are available on the current market.
\end{abstract}

Keywords: mass customization; toolkit design; evaluation model; 3D toolkits.

\section{INTRODUCTION}

Mass Customization (MC) has attracted considerable attention and has evolved significantly over recent decades in both academia and industry. The term "mass customization" was introduced by Davis in 1987 and was considered to be a new approach to business where companies attempt to offer unique products and services to customers [16]. Davis emphasized the paradox of MC - it 'is understood to be both part (customized) and whole (mass) simultaneously' [17]. In other words, MC on one hand attempts to satisfy the specific needs and desires of individual customers; while on the other hand it is supposed to provide products and services for a relatively large market. [66] further developed the concept and considered it as "a synthesis" of mass production and customization, i.e. "the mass production of individually customized goods and services". As broader applications emerged in industries, MC tends to be conceptualized from more practical perspectives, such as "a strategy that creates value by some form of company-customer interaction at the fabrication/assembly stage of the operations level to create customized products with production cost and monetary price similar to those of mass-produced products." [44]. Despite having various definitions, the concept of 
MC is centered on "producing goods and services to meet individual customer's needs with near mass production efficiency" [79].

Toolkits have been widely used in industry as a medium between consumers and manufacturers. The MC Toolkit is not a new concept. It is also known as a product configurator [50], configuration system [48], design system, co-design platform [23]. However, as opposed to a set of tools that would be employed by manufacturers in mass production, the mass customization toolkit is a technology that allows consumers to design their own products or service and also delivers immediate feedback of the potential outcome of their design ideas [34], [65], [53]. In this case, the toolkit transfers design abilities from manufacturers to consumers, while it also translates consumers' design ideas to a producible language required by production systems [27], [34], [24]. This leads to two benefits: first, shifting the need-related development tasks from manufacturers to the consumers in a relatively lowcost and swift way; and second, developing products and services specifically tailored to each consumer's needs and requirements [24]. Therefore, as the primary communication tool between consumers and manufacturers, the toolkit ultimately determines the success or failure of mass customization, and the design of the toolkit should be placed at the heart of building mass customization systems [27], [53].

Nevertheless, toolkit design is a complicated task. Since most toolkits nowadays are computerbased and especially web-based [23], [32], [65], from the consumer's point of view they are like a set of interfaces which requires the consumer's input and also provides immediate feedback to the consumer. Typically, toolkit design needs to consider the consumer experience during the process of customization and aims to create a satisfying experience for consumers so that it can help to increase consumers' loyalty to a company [23]. Meanwhile, toolkit design is also closely related to technology development [48], [71]. In essence, web technologies enable the possibilities of consumer interaction. Furthermore, the development of geometric modeling provides the means of presenting a virtual 3D product which can be easily customized. In this article, we refer to 3D MC toolkits as those web-based virtual product environments that allow for visual presentation, interactive user manipulation and editing of 3D product designs in a seemingly real or physical manner. Although most existing mass customization toolkits are based on text and 2D graphics [48], [50], there are a number of attempts of using 3D models to visualize customizable products, e.g. Uformit (https://www.uformit.com/, accessed on 26/11/2016), Nervous System (http://n-e-r-v-o-u-s.com/, accessed on 26/11/2016).

To achieve effective mass customization it is therefore vitally important that $3 \mathrm{D}$ toolkits are designed to elicit a satisfying consumer experience. In working towards this goal, this article provides an overview of web-based toolkit design, focusing on academic and theoretical research in MC toolkit design. By analyzing and categorizing previous studies, an evaluation model is proposed which is specially designed for evaluating 3D MC toolkits.

In order to make the valid inference from relevant literature, content analysis has been used as the method to drive the survey analysis. Following an inductive reasoning approach, the aim of our literature review is to identify the design guidelines or principles for mass customization toolkit design in existing studies. Two key words have been used to determine particular literature to be collected as data for analysis: mass customization and toolkit design, and latent analysis is adopted to find the underlying meaning of the data to an interpretive level. After a few cycles of decontextualisation and recontextualisation, the relevant content has been categorized and presented in the following section.

\section{LITERATURE REVIEW}

The primary task of a mass customization toolkit is to help consumers as they design or modify a product or service to meet their needs and requirements. However, studies have shown that most consumers do not know what they actually want at the beginning of the design process, or that sometimes even if they know what they want, it is difficult for them to describe [34]. In this case, a toolkit which provides consumers with opportunities to discover their needs and then translate these needs into a set of adjustable parameters is required. In other words, a toolkit should be designed to offer a complete 'trial-and-error' cycle, i.e. where consumers can "learn what is possible, try different possibilities, learn from errors, compare different solutions, and thus conduct a time consuming, 
iterative learning process" [23]. Based on this 'trial-and-error' design requirement, another four elements have been identified for designing an effective toolkit: solution space, user friendly interface, module libraries and producible custom products and service [34]. These elements are proposed preferably considering consumer participation, but neglecting the influence of underlying technologies as an important support and determinant for the implementation of toolkits.

[23] proposed three main components of a toolkit: core configuration software which provides design options and guides consumers through the configuration process; a feedback tool which gives feedback information and visualizes design variants; and analyzing tools, translating consumer designs into construction plans. These three components cover almost every aspect of toolkit design, however, it separates consumer-toolkit interaction into two parallel processes - guiding consumers through the configuration process and giving consumers feedback information. In practice, the two processes are closely related and intersect with each other. For example, a good toolkit design will provide immediate feedback after the consumer interacts with the toolkit every time.

Given these considerations, in this article we investigate toolkit design from four aspects: solution space - covering design options for customization; interaction design - the process of customization, including guiding consumers through customization and providing immediate feedback information; 3D modeling technologies - techniques supporting 3D product visualization; and the influence of individual differences on toolkit design. At the end of this section, a table is presented to show the comparative analysis of the four aspects.

\subsection{Solution Space}

Solution space is understood as all the possible designs a toolkit can provide [31]. It decides the design freedom that a toolkit can offer to a consumer. Typically there are two elements related to the design of the solution space: the type of options it provides and the size of the choice set, which is literally the size of the solution space.

\subsubsection{Type of Options}

The type of options is largely determined by the way that a product can be customized. Hermans examined a number of online mass customization toolkits and categorized four different mechanisms for customization [31]. In his opinion, the most common way of offering customization is a method he termed Veneer, which allows consumers to customize products by adding a visual decorative layer to a product (Fig. 1). Therefore, the possible options for this mechanism include a list of different texts, graphics, patterns or colors which can be added to the surface of the product by processes such as printing, engraving, etching or embroidery. The second customization approach is Modularity, where products are decomposed into a set of discrete modules and options for their assembly into a customized design are presented to the user. A typical example of this approach would be found on a computer manufacturer's website, where the user can customize their computer by selecting between different functional components, such as processor speed or amount or memory (Fig. 2). The individual options in this approach usually feature different component designs or functions. The third mechanism of customization is Parametric customization. This approach is widely used in 3D toolkits, which allow consumers to customize a product by changing specific parametric values which then change the nature of the product in some way. For example, the online customization website Uformit enables consumers to change the dimension, structure, shape and material of a product (Fig. 3 ). Some of the parametric features are inter-related, so changing one parameter can also lead to related features changing dramatically. In addition, biometric scanned data is also considered as an important parameter by many manufacturers. For example, Uformit allows consumers to upload scanned data of their faces, which is then treated as another parameter - for example, to modify a mask to exactly fit their face. The fourth mechanism identified by Hermans is Generative customization, which creates 2D or 3D forms based on built-in generation procedure. For example, consumers can sketch the side view of a lamp and extrude it into a 3D model (Fig. 4). 


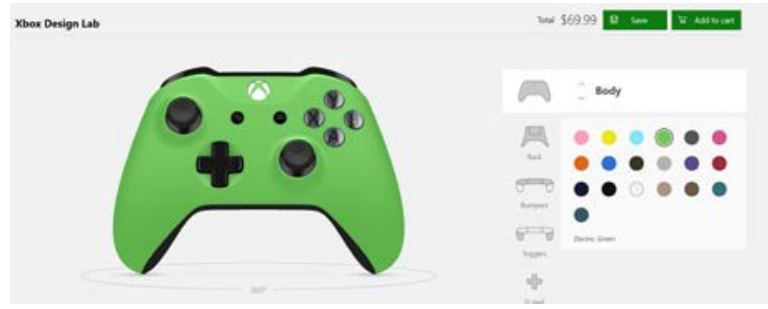

Fig. 1: Veneer customization approach for Microsoft Xbox

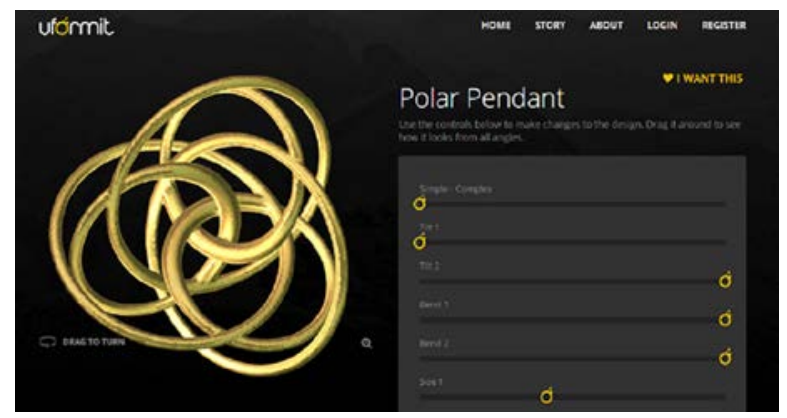

Fig. 3: Parametric customization approach for Uformit

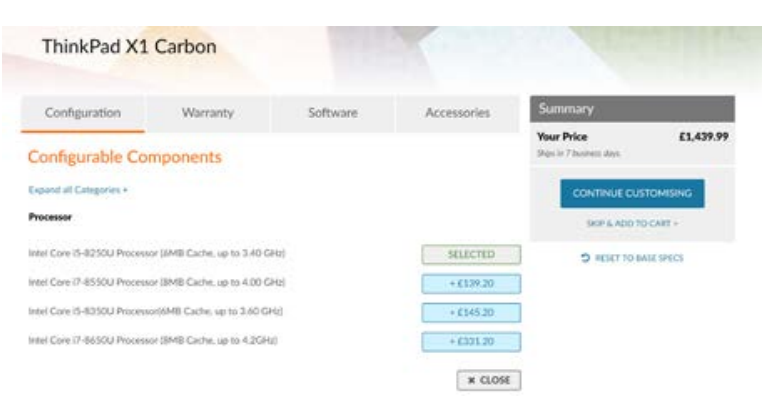

Fig. 2: Modularity customization approach for Lenovo ThinkPad
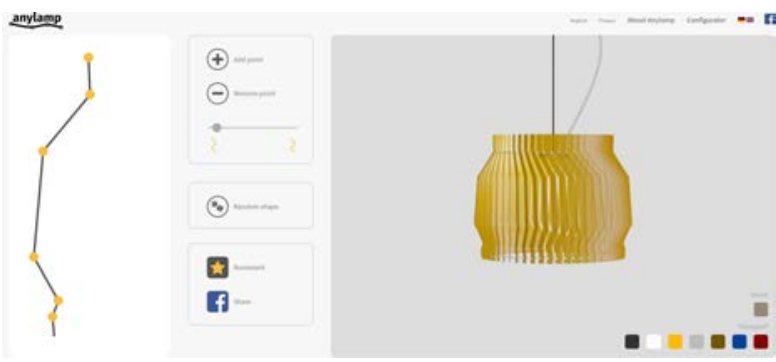

Fig. 4: Generative customization approach for Anylamp

In addition to offering different types of options by considering the method of customization, some researchers agreed that toolkits allow consumers to engage in utilitarian, kinesthetic or visual customization based on the functions a product can possess, and similar classifications were also defined as functionality, fit (ergonomic) and style (aesthetic) [60], [8]. [50] extended this finding to five dominant types of options: fit, function, aesthetic, quality grade and packaging. In particular, a number of researchers focused on the functional and aesthetic options offered by MC systems, and found that they can lead to different consumer behaviors [72], [14], [18], [7].

Specifically, functional choices require less spontaneous elaboration than aesthetic choices, and aesthetic choices tend to be easier to imagine and to elaborate than functional choices [72]. This was identified to be because consumers' choices of functional features reduce down to problem-solving, which is a cognitive-driven process [72], [38]. In contrast, the process of choosing aesthetic features is related to an enjoyable experience and positive or negative feelings, which are more likely to be driven by affective (emotional) processes [10], [37]. In this sense, [72] suggest that providing consumers with aesthetic choices should be the main approach to mass customization, because consumers enjoy themselves more when they customize aesthetic features than functional features, regardless of individual ability differences.

\subsubsection{Size of Solution Space}

The size of the solution space is the range of unique final products that a toolkit can produce, considering both the range of the parameterization options and the number of steps between them. It is determined by two factors: the number of attributes for customization and the variety of values given by each attribute. For example, color is an attribute and yellow is one value of color. However, the ideal size of the solution space is still a matter of debate. On one hand, results of empirical studies by inviting participants to customize a product using existing toolkits have shown that consumers are actually disappointed by the limited choices offered by most existing toolkits [48]. Other studies indicated that the majority of consumers would like to have more and a larger variety of choices and also play a more active role in the design of products [24], [51], [25]. On the other hand though, it has been found that consumers can be overwhelmed by the number of choices provided by manufacturers, 
which may lead to 'mass confusion'. This is because excessive choices result in information overload [23], [82], [52].

Since consumers sometimes lack the ability to process overloaded information, they feel confused and annoyed when they are offered too many choices [23], [65], [53], [54], [55]. As a result, this has a negative influence on consumer enjoyment of customization and the satisfaction in producing the final product [53]. Although information overload is not the only reason for mass confusion, it has attracted a good level of attention in the literature. [40] found that the relationship between consumer satisfaction and the number of choices can be demonstrated in an inverted U- shaped fashion, i.e. after reaching a certain point, the more choices provided, the less satisfied consumers are. Another proposed approach to this problem is to convert the number of choices into the number of products in a bricks-and-mortar store to get an adequate understanding of how many choices the customer has [23].

\subsection{Interaction Design}

For online customization, the process of customizing a product is fundamentally a process of humancomputer interaction. The quality of the interaction is crucial for the success of mass customization as it determines whether or not the consumer will be able to complete the customization task [78]. Considering consumer interaction with toolkits as a creativity activity, [28] proposed nine design principles to support and encourage consumers' participation: provide an optimal challenge; provide autonomy; provide a community; give permission to take risks; facilitate goal setting; support positive affect; encourage mastery experiences; provide resources; provide encouragement. These nine principles cover different aspects of the interaction between consumers and toolkits. To aid discussion, in this article we categorize the different aspects of interaction design as: Procedure Design, Design Guide, Direct Manipulation and Collaboration Design.

\subsubsection{Procedure Design}

[28] suggest that the customization task should be set up step by step as a series of smaller tasks with increasing challenge which helps consumers to avoid getting bored or getting confused. Meanwhile, multiple pathways should be provided to allow consumers to choose their own progression, which helps to give them feelings of autonomy, ownership and control over their creation process [84].

This suggestion has been echoed by [48] who agreed that products which require consumer creativity should be customized in a flexible design procedure. However, for products that require more functionality customization, research undertaken by [47] proposed a top-down hierarchical approach where general features of product functionality are selected prior to detailed design features. For example, in a watch design toolkit, choices of type of watch, shape, face, etc. should be provided before choices of dial, numeral, etc. Regardless of which approach a toolkit design follows, [34] suggests that providing consumers with enough information about the design procedure to let them know which step they are currently in and how many steps there are until completion is very necessary.

\subsubsection{Design Guide}

A usable toolkit should provide consumers with clear and proper guidance through all stages of the customization process. Meanwhile, it should inspire consumer creativity by offering existing design templates, and more importantly it should encourage consumers to go beyond what they or others have done before.

[28] suggest that a "how-to" video tutorial, a help menu and clickable paths to further explanations can be used as support resources for consumer interaction, but they must not overwhelm the consumer. In addition, a real-time help also contributes to the creation of a safe environment for new consumers while also encouraging more experienced consumers to challenge themselves in their creativity and designs [28]. In order to encourage consumer creativity, [34] claimed that libraries of standard modules should be provided to consumers to help them focus their creative work on those aspects of their design that are truly novel. A few researchers [34], [65], [32] also agreed that a preset design at the starting point is useful to make the process more accessible for consumers. 
It is also necessary to prioritize the customizable options or to provide navigation between choices for toolkits with a large solution space [31].

\subsubsection{Direct Manipulation}

Direct manipulation includes the application of real-world metaphors to make the interaction easier for consumers to learn. In addition, the rapid feedback allows consumers to see the results of their actions, therefore giving them a sense of control and strengthening their beliefs about their ability to take further interactions [6]. A number of researchers [48], [58], [59] agreed that 3D toolkits are more effective and satisfying than 2D toolkits. Furthermore, [28] suggest that 3D toolkits should allow consumers to operate directly on tools or 3D models and receive instant feedback for their choices.

\subsubsection{Collaboration Design}

According to [43], the internet has prompted a "participatory culture" which shifts the focus of interaction from one of individual expression to a collective of individual involvements. Participatory culture encourages new consumers to engage and learn, and also supports experienced consumers to share and develop together to create a meaningful design that also reflects their own creativity. [65] believed that the collaboration between consumers helps to foster joint creativity and problem solving as well as reducing the perception of risk. Therefore, it is useful to provide an online community, such as a chat room, for instant communication [65], [28]. In addition, [28] suggest providing a library of consumer-created designs to guide and inspire further product developments and a historical record of work and progress of consumer collaboration around a shared interest. [65] also believe that it would be helpful to provide space for consumers to leave comments or to assess contributions from each other.

\subsection{Enabling Technologies - 3D Modeling and Web Technologies}

\subsubsection{D Modeling Technologies}

As previously mentioned, MC toolkit design is closely related to technology development. Specifically, 3D modeling and web technologies are the two key enabling technologies for web-based 3D toolkit design and consumer interaction. A variety of 3D modeling technologies and web technologies has been developed and capabilities of different technologies ultimately dictate what is possible in terms of both the solution space and also the interaction techniques that are available. It is therefore important to consider this layer in order to fully analyze the capabilities of the MC system. In this section we outline from a technical perspective the main trends in design tools with 3D modeling in their core.

The 3D modeling technologies are those which describe the physical shape of the product [35]. This is a virtual representation that is originally defined by the product designer and must be adjustable by the end-user through the interaction design method. 3D modeling technologies are often known as "shape modeling" in the area of computer graphics, which has been used as a generic term for geometric modeling embracing various approaches to representing 3D products. At present, the discipline of shape modeling is in transition from an established design paradigm to a new one and this is driven by the fundamental requirements that MC rely upon.

Classical design paradigms concentrated on obtaining one specific final shape. The design process supposes that designer first conceives a comprehensive model specification and transfers it to the computer through a textual or graphic interface; then the modeling system (integrated with built-in computing and rendering procedures), produces a result which usually has the expected appearance. For example, if a designer wants to generate a 3D tea cup model, the first step he/she needs to do is designing the tea cup with a comprehensive model specification. He/she can use 3D modeling Computer-Aided Design (CAD) software to transfer their design to the computer, and then the modeling system will produce a tea cup model for the designer just as what he/she expected.

The new design paradigm is quite different to the established practice. Instead of leading to the virtual description of one final product shape, it is oriented more towards defining a parametric family of shape instances, i.e. a set of inter-related models. These parameters are built into the model description and allow the shape to be changed in some way. Such novel parametric modeling systems emphasize the importance of the design process and focus on the means of creating models. In order 
to customize a product initially created by professional designers, it is vital to emphasize the technical provision for generating a generic parameterized shape that can be adjusted according to individual consumer's needs. This is the case for every step of the creation pipeline, from initial model description by the professional designer, to the point of consumption.

Another major requirement of modern parametric modeling systems is to be able to create and modify the volume of a 3D model with a complex internal structure [64]. This mainly aims to meet the manufacturing requirements of 3D printing as a means of producing MC products. Conventional 3D models are usually surface-based representations that are not naturally suited to 3D printing. This requirement means a shift from a conventional surface-based solid object representation to hybrid representations combining surfaces and volumes as well as introducing an associated set of internal physical properties of heterogeneous volume objects, such as material, density, microstructure, color and others.

\subsubsection{Parametric Modeling and General Approaches}

The main principle of MC is that the user changes a product through an interactive process. In a 3D MC approach, as the user interacts with the system the actual shape of the product changes in some way. For this to be possible, the modeling technology has to define not just a single shape but a whole family of shapes. The ways in which the shape is changed from one to another defines the interaction design possibilities and the range of valid shapes defines the solution space.

The method of using adjustable values within a geometric model to change its shape is known as parameterization and is essential in interactive modeling based on user-modifiable definitions [74] and in optimizing shapes to satisfy some design criteria [13]. Mathematical, algorithmic, and software support for defining a parametric family of shapes, such that each new set of parameter values corresponds to another valid instance of a shape, is one of the ultimate goals of shape modeling research and development. It is this parameterization of the model that makes full 3D MC possible and different methods of parameterization offer different interaction types and different solution spaces. Further, a professional designer and a non-professional consumer have to deal with the same parameterized model using different levels of access to it. For example, a professional designer can decide which parameters consumers can customize while consumers can only interact with the parameters that the designer selects. Again, different modeling technologies offer different methods and possibilities for each of these levels.

Let us first consider different approaches to the parameterization problem, before applying them to specific methods of representing the 3D geometry and finally considering what web technologies are required to drive them.

A pure parametric approach allows the parameters to be embedded into the actual definition of the model. This is a very direct approach offering little ambiguity from an interaction perspective. For more complex models it may be necessary to combine parameters in some mathematically relational manner so that adjusting one parameter from the user interface side can alter several in the model.

Another approach which is a natural extension of a pure parametric form is to define the construction of the model in some combination of component parts and modeling operations. Here, parameters may exist in both the components and the operators. A tree-based structure is a common approach. Here, the leaves of the tree are typically primitive shapes and the connecting nodes are operations [36].

In a history based approach [49], each step in the designer's construction process is recorded. An approximation to parameterization is then achieved by 'rewinding' the history to a point, changing the geometry in some way, and then 'reapplying' the operations. This can work in certain limited circumstances, depending on how the model is represented or the nature of the change, but frequently the changes are unpredictable or do not reapply in a way that makes sense for the designer or user.

In the procedural or generative approach a set of computer instructions are written which construct the model using the chosen representation system [76], [30], [75]. These instructions can take user input as a parameter, incorporate them into the procedure to allow the physical shape to change and therefore enable an exploration of the solution space. This technique is very flexible, but requires careful crafting of the procedure, which can be a difficult and involved process. 


\subsubsection{Representational Modeling Schemes}

Solid modeling is a subject that developed out of engineering requirements and is essentially a means of describing a complete physical object without mathematical or procedural ambiguity [73]. Mathematical models are employed as the building blocks for representation modeling schemes, which describe the actual shape of the product. There are many representation modeling schemes available, some of which natively offer more interaction methods than others and some are easier or more intuitive for the product designer to give a broad solution space than others. Here we will briefly introduce different modeling schemes.

The earliest approach to solid modeling where model parameterization was essential is primitive instancing. In primitive instancing, the geometric objects are parameterized with a built-in set of parameters, and changing parameter values results in a new primitive instance. For example, a ring is parameterized with internal and external radii and a material index. This approach was oriented to a specific area and did not address more general forms of modeling [69], [70].

Another common scheme is Boundary Representation (BRep). As the name indicates, in BRep solid objects are modeled by defining their piece-wise boundary. The simplest example of BRep is a triangular or polygonal surface mesh. However, it is hard to directly parameterize polygonal meshes, because it needs to establish dependences between parameters and coordinates of each mesh vertex. In addition, for BReps with spline surfaces or algebraic surface patches, parameterization is not well defined and limited [74]. For example, objects with different topology (e.g., a sphere and a torus) cannot belong to the same parametric family of BRep solids. In spite of these limitations, modern commercial systems (e.g., most CAD software) support parametric solid modeling based on BRep.

The parameterization available with BRep approaches is limited. It is trivial to allow scaling operations (including in separate dimensions) of the whole object. Similarly, if the object consists of separate parts these may be scaled or moved in relation to one another, but the problem remains on how to combine the separate parts at the end of the process (especially if 3D printing is chosen as the fabrication method) and how to ensure that parts remain constrained to one-another in a continuous whole - for example, moving the handle of a teacup completely away from the container such that the two are no longer connected. A procedural construction method may be used to create BRep geometry in a manner that offers further interaction possibilities and a wider solution space, but again such procedural instructions are difficult and time-consuming to write.

Constructive models such as obtained using Constructive Solid Geometry (CSG) allow for more flexible parameterization supporting to some extent changing topology of the object [74], [12]. CSG uses a tree-based approach and potentially offers more powerful interaction methods than BRep. Limiting to just scale and movement / orientation, the fact that separate component shapes can be easily added and subtracted from one-another immediately offers a broader solution space before having to move on to a procedural construction. When combined with primitive-instanced solid modeling, the inbuilt parameterization of the primitives themselves offers further flexibility. However, parameterization with smooth transition between radically different shapes is problematic and traditionally the range of operations is limited.

Function Representation (FRep) [63], [62] provides functions that allow points in space to be tested for whether or not they are inside or outside the object. As such it is a generalization of implicit surfaces, CSG, sweeping, and other shape models. It easily allows for parameterization, description through high-level languages and web-applications [2]. FRep offers a higher level of parameterization of shape models, giving a broader range of interaction possibilities. Depending on the parameter variations, objects can completely change their geometry and topology thus providing the designer a high level of creative freedom and broader solution space [3]. However, this power and flexibility does come at a price and perhaps the primary disadvantage is its high computational cost, which makes it slow to interact with and render the models.

Both BRep and FRep have their advantages and disadvantages. In such a demanding area as creating sophisticated parameterized products with subsequent 3D printing it is natural to aim at using the best of both worlds. Our hypothesis is that the most suitable theoretical framework is related to the hybrid modeling of heterogeneous objects that combines a traditional BRep of the object (polygonal meshes and parametric surfaces) with the mathematically precise FRep volume representation allowing for modeling of the object's internal structure in terms of both the geometry

Computer-Aided Design \& Applications, 15(a), 2018, bbb-ccc (c) 2018 CAD Solutions, LLC, http://www.cadanda.com 
and attributes (different materials, physical properties, etc.). The CAD tools of new generation based on that representational paradigm will provide a wider range of shapes and operations on them thus supporting more application areas. There are a few prototype implementations of such hybrid modeling systems [4], [5], with applications in computer animation and CAD, oriented to modeling and fabrication of heterogeneous objects [64].

This approach would allow for addressing emerging new requirements for prospective MC systems such as multi-material modeling. Multi-material 3D printers are already available on the commercial market and some initial modeling solutions exist, such as OpenFab [80]. However, there is a need in interactive modeling tools with a set of specific modeling operations allowing for distributing different materials in the design space and mixing or blending them. This would naturally present an ever broader solution space but the interaction approach is current unclear.

\subsubsection{Enabling Web Technologies}

For the purpose of web-based MC, the end-user needs to interface with the 3D model, to view it and customize the product. Full CAD software is not available or suitable for this application, so lighter weight solutions are needed that run from a web-browser.

The basic tools available within a web-based environment are HTML and JavaScript scripting language [77]. Some special purpose functionality can be achieved through implementing a small application called an applet which is sent together with the Web page to the user and can typically be implemented in the Java language [11]. To handle full interactive 3D graphics the toolkit needs to employ HTML5 and WebGL [61].

These technologies will allow the user to interact with a local representation, where the 3D object and means of interaction are based in their web-browser. In some cases there can be a high computational requirement, especially when modifying the model using a more powerful representation scheme. In such cases it is likely that the local machine, which could be a portable device such as a smartphone or tablet, is insufficient to handle the requests. Here, some or all computations may be handled by a server that the website contacts in the background to perform the heavier computations [1].

\subsection{Individual Differences}

As discussed previously, toolkit design is a complex topic that is primarily concerned with creating a satisfying consumer experience. However, every consumer is individual and unique, each with their own skills, aesthetic tastes and physical requirements. In order to create a toolkit that satisfies each consumer, the design of a toolkit must account for these individual differences [72], [53], [21], [26], [9].

The model of competency has been applied to explain the interconnection between toolkits and individual differences that may affect consumer involvement, i.e. mind, knowledge and skill [32], [33]. It further examined consumer behaviors during customization and identified four different consumer models, or 'characters', to categorize consumers: Settlers, Voyagers, Strollers and Horsemen.

Settlers explore almost every choice in the toolkit and create a completely different design from the default design provided at the start point. Voyagers also examine choices, but eventually return to their starting point and thus they end with a similar design. The Stroller focuses on a small set of choices in an intense way; therefore, they like to go back and forth many times. The Horseman on the other hand explores all the choices with great speed, often from one end to the other [32]. The four characters thus represent four different consumer behaviors in customizing a product. In addition, consumer enjoyment during the process of MC and their satisfaction in the final customized product are different as well. [22] found that customers who have strong insights into their own preferences and who know what they want tend to enjoy the process more than customers who lack this preference insight. [41] proposed three variables which are associated with individual differences and consumers' perceived value of mass customized products, namely a need for optimization, a need for uniqueness and centrality of visual product aesthetics. They found that consumers with a higher need for optimization, a higher need for uniqueness and a higher proclivity towards aesthetics tended to be more satisfied with the final product.

In addition, a number of studies agreed that toolkit design should be concerned with individual differences in knowledge, skills, creative talent even previous experience in mass customization [72], 
[53], [21], [26], [9]. [72] suggest that for consumers who are highly knowledgeable about customizing products, a complex toolkit that provides them with a large number of options is better suited. Similarly, consumers with more internet experience prefer more substantive features in a toolkit to those with less experience [9].

In comparison, for less experienced consumers, more guides through the configuration process are necessary, and the size of the solution space should be limited to a few customization possibilities [72], [53]. [68] claimed that consumers who have greater expertise in a product domain are better served by a parameter-based interface, whereas lower expertise consumers are better served by a need-based interface. [81] argued a programming interface is more efficient for experts in computer technology, and professional designers who offer original designs for customization should be provided with a different interface and a set of different tools within the same toolkit when compared to ordinary consumers who co-design the final products.

In order to benefit different consumer groups using one toolkit, an adaptive and graded approach has been proposed [24]. [53] suggest that a brief introductory assessment of consumers' knowledge (e.g., product knowledge or previous experience with product configuration) should be integrated into the beginning of the configuration process. Then, according to the assessment results, a different solution space is presented to the consumer. In addition, as the less experienced consumers become more familiar with the customization process, more challenging toolkits should be offered to them, which they can then choose on a voluntary basis [53].

\begin{tabular}{|c|c|c|}
\hline \multirow[t]{4}{*}{ Solution Space } & \multirow[t]{2}{*}{ Type of Options } & $\begin{array}{l}\text { Different mechanisms for customization: veneer, } \\
\text { modularity, parametric and generative [31] }\end{array}$ \\
\hline & & $\begin{array}{l}\text { Different options for customization: functional and } \\
\text { aesthetic options [72] }\end{array}$ \\
\hline & \multirow[t]{2}{*}{$\begin{array}{l}\text { Size of Solution } \\
\text { Space }\end{array}$} & $\begin{array}{l}\text { Consumers prefer a larger variety and quantity of choices } \\
{[24],[51],[25]}\end{array}$ \\
\hline & & $\begin{array}{l}\text { Consumers feel confused and annoyed by overloaded } \\
\text { information [23], [65], [53], [54], [55] }\end{array}$ \\
\hline \multirow{13}{*}{$\begin{array}{l}\text { Interaction } \\
\text { Design }\end{array}$} & \multirow[t]{4}{*}{ Procedure Design } & Provide step by step tasks with increasing challenge [28] \\
\hline & & Provide multiple pathways [84] \\
\hline & & Creativity tasks follow flexible design procedure [48] \\
\hline & & $\begin{array}{l}\text { Functionality tasks follow top-down hierarchical design } \\
\text { approach [47] }\end{array}$ \\
\hline & \multirow[t]{4}{*}{ Design Guide } & Provide support resources for consumer interaction [28] \\
\hline & & Provide libraries of standard modules [34] \\
\hline & & Provide a preset design at the starting point [34], [65], [32] \\
\hline & & Prioritize the customizable options [31] \\
\hline & \multirow{2}{*}{$\begin{array}{l}\text { Direct } \\
\text { Manipulation }\end{array}$} & Provide rapid feedback [6] \\
\hline & & Provide direct manipulation on 3D toolkits [28] \\
\hline & \multirow{3}{*}{$\begin{array}{l}\text { Collaboration } \\
\text { Design }\end{array}$} & Build up collaboration between consumers [65] \\
\hline & & $\begin{array}{l}\text { Provide a historical record of work and progress of } \\
\text { consumer collaboration [28] }\end{array}$ \\
\hline & & Provide space for consumers to leave comments [65] \\
\hline $\begin{array}{l}\text { Enabling } \\
\text { Technologies }\end{array}$ & $\begin{array}{l}\text { 3D Modelling } \\
\text { Technologies }\end{array}$ & $\begin{array}{l}\text { Different approaches to parameterization: pure parametric } \\
\text { approach, history based approach [49], procedural or } \\
\text { generative approach [76], [30], [75] }\end{array}$ \\
\hline
\end{tabular}




\begin{tabular}{|c|c|c|}
\hline & & $\begin{array}{l}\text { Different solid modeling schemes: primitive instancing } \\
\text { [69], [70], Boundary Representation (BRep) [74], } \\
\text { Constructive Solid Geometry (CSG) [74], [12], Function } \\
\text { Representation (FRep) [63], [62] }\end{array}$ \\
\hline & Web Technologies & HTML and JavaScript scripting language [77] \\
\hline \multirow[t]{3}{*}{$\begin{array}{l}\text { Individual } \\
\text { Differences }\end{array}$} & & $\begin{array}{l}\text { Individual differences in knowledge, skills, creative talent } \\
\text { and previous experience [72], [53], [21], [26], [9] }\end{array}$ \\
\hline & & Provide an adaptive and graded approach [24] \\
\hline & & $\begin{array}{l}\text { Provide a brief introductory assessment of consumers' } \\
\text { knowledge at the beginning of the configuration process } \\
\text { [53] }\end{array}$ \\
\hline
\end{tabular}

Tab. 1: Summary of comparative analysis of relevant literatures

\section{A MODEL FOR EVALUATING ONLINE 3D TOOLKITS}

Despite the significant amount of effort that must have collectively gone into building the web-based 3D MC systems, currently there is no widely-accepted model or criteria to evaluate these systems, especially in terms of toolkit design. Given these considerations, and based on the literature review in section 2, we propose a new model - an Online 3D Mass Customization Toolkit Evaluation Model to evaluate online 3D mass customization toolkits with the focus on consumer experience as well as the underlying technical supports and their influence on the design of 3D toolkits (Fig. 5).

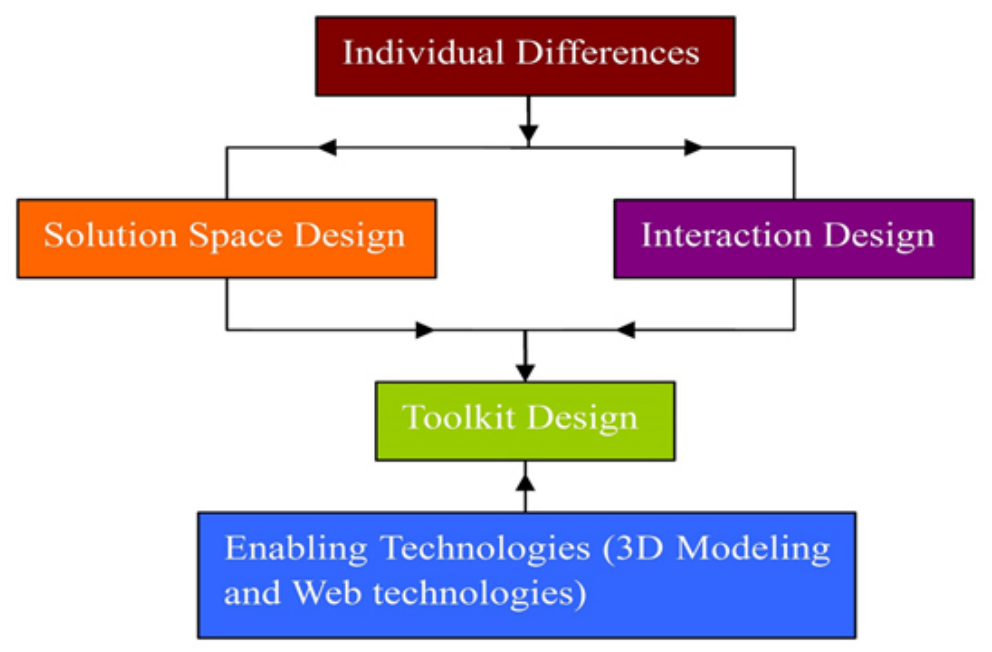

Fig. 5: Online 3D Mass Customization Toolkit Evaluation Model.

The center of the evaluation model is the toolkit design. This is driven by the underlying technologies, which offer features or limitations to the toolkit design. The interaction design defines the process of customization while the solution space provides the design possibilities. In addition, individual differences are also an important factor to evaluate because they help to create a satisfying experience for different consumers. In this sense, the evaluation model has been designed from four perspectives: solution space design, interaction design, supporting technologies (i.e., 3D Modeling Technologies and web technologies) and individual differences. 


\subsection{Solution Space Design}

The solution space in this model is used to evaluate how diverse and how large the solution space is, i.e. the variety and quantity of potential designs a toolkit can provide. It is concerned with two aspects: the types of customization options a toolkit provides and the size of the solution space. The types of options, as reviewed in section 2.1, could be veneered, modular, parametric or generative alternatives when considering the approach to mass customization, and then either functional or aesthetic options when considering the purpose of the product changes. The size of the solution space is usually represented by the number of potential final designs a toolkit can provide.

\subsection{Interaction Design}

The interaction design criteria here represent the evaluation of a comprehensive process. It does not only include interactions between consumers and the toolkit, but also refers to interactions between consumers as well as interactions between consumers and manufacturers. Further, interaction design does not only consider the process of consumer participation, but also considers how a toolkit should respond and adjust itself to consumer participation. Based on the review of current research in section 2.2, the criteria for evaluating the interaction design are listed in Tab. 2.

\begin{tabular}{|c|c|c|}
\hline Categories & General principles & Guidelines \\
\hline Procedure Design & $\begin{array}{l}\text { Provide an engaging and } \\
\text { autonomous design } \\
\text { procedure and support } \\
\text { consumers' "trial-and- } \\
\text { learning". }\end{array}$ & 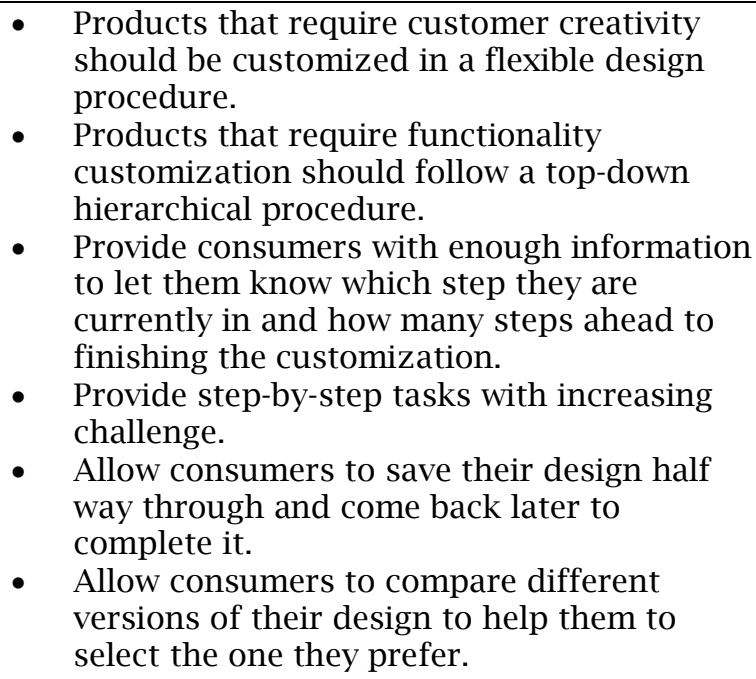 \\
\hline Design Guide & $\begin{array}{l}\text { Provide clear and easy- to- } \\
\text { understand guide and } \\
\text { support as needed for the } \\
\text { consumer at all stages of the } \\
\text { customization process. } \\
\text { Consumers should be } \\
\text { inspired and encouraged for } \\
\text { their innovation. }\end{array}$ & 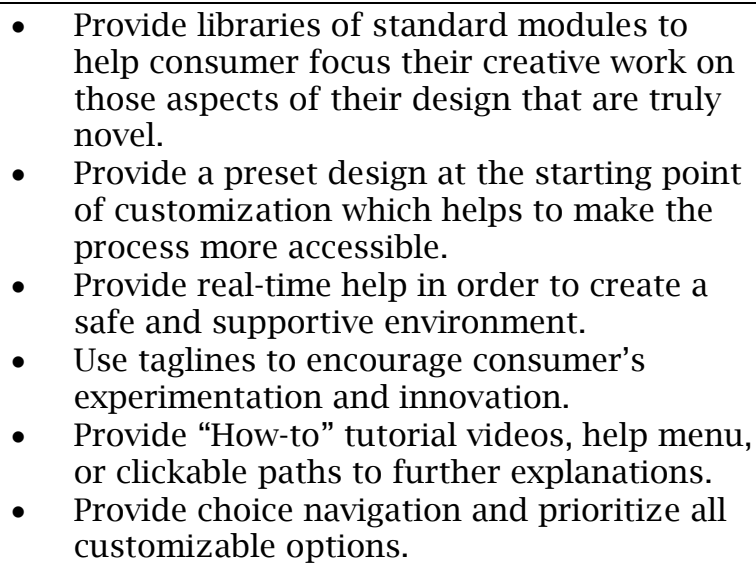 \\
\hline
\end{tabular}




\begin{tabular}{|c|c|c|}
\hline \begin{tabular}{|l|} 
Direct \\
Manipulation
\end{tabular} & $\begin{array}{l}\text { Provide consumers with the } \\
\text { sense of control and allow } \\
\text { them to directly manipulate } \\
\text { the 3D model. }\end{array}$ & $\begin{array}{l}\text { Allow consumers to directly manipulate } \\
\text { tools or 3D models for customization. } \\
\text { - Provide instant feedback of consumer's } \\
\text { choices to give them a sense of control. }\end{array}$ \\
\hline $\begin{array}{l}\text { Collaboration } \\
\text { Design }\end{array}$ & $\begin{array}{l}\text { Provide communication } \\
\text { opportunities among } \\
\text { consumers and encourage } \\
\text { them to share, create and } \\
\text { learn together. }\end{array}$ & 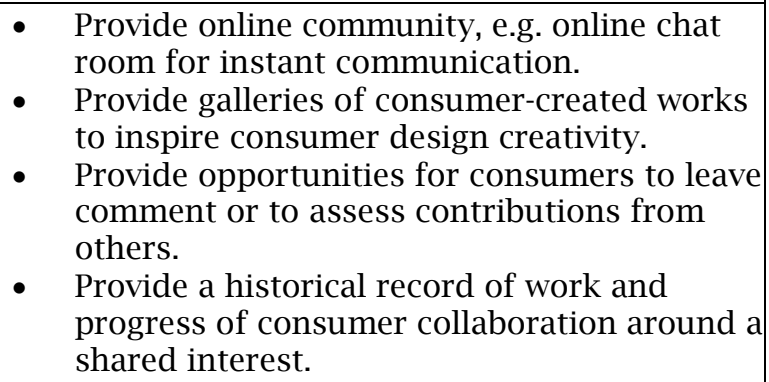 \\
\hline
\end{tabular}

Tab. 2: Evaluation principles and guidelines for interaction design of toolkits.

\subsection{D Modeling and Web technologies}

The evaluation criteria from the 3D modeling technology lead on from the literature review in section 2.3 and are broken down into four evaluation categories:

- The representation modeling scheme. Here, we distinguish between polygonal meshes or other boundary representations based on parametric surfaces, constructive modeling schemes and function representation, as described in section 2.3. These can give us insight into what features are offered to the toolkit design.

- The level of the model parameterization. This directly enables the toolkit to offer both interaction design capabilities and the existence of the solution space. The level of model parameterization can vary from a very basic level with simple transformations (such as scale, rotation) to a high level with support for radical changes to the shape of the product (changing the actual shape, adding holes, additional geometry etc). The level of parameterization is closely connected with the representation scheme. For example, typically boundary representations allow only for a basic level. However, if generative modeling is employed, a very high level of parameterization can be achieved, although at a high cost.

- The level of designer's support for modeling and uploading new designs. This shows how much effort a designer applies to produce a new parameterized model and to make it available to customers. For example, generative modeling for boundary representations typically requires programming a new applet or plug-in to produce a design instance for the given set of parameters. On the other hand, function representation allows for a simple save and upload procedure as the representation itself supports a high parameterization level.

- Required web technologies. Here we distinguish between basic toolkits with HTML and JavaScript implementations, advanced with Java applets and highly 3D interactive with HTML5 and WebGL employed. The required technologies can influence how the site can be viewed (e.g. on smartphone / tablet, or PC) which can further affect the consumer experience.

\subsection{Individual Differences}

The consumer is a very important dimension to consider for toolkit design, because different consumers may have different experiences during their interactions with the toolkit. In this case, the consideration of the consumer's influence on toolkit design mainly focuses on the differences between individual consumers. Individual differences here are used to assess the ability of a toolkit to consider each consumer's differences in previous experience, knowledge, ability and skills. Typically, an adaptive approach for toolkit design is required in order to design a toolkit tailored to each consumer's differences. Based on the review of current studies, this can be achieved through three approaches: 
- Provide different starting points by assessing consumer's previous experience of using the toolkit - the toolkit can 'remember' previous difficulties or successes for consumers to complete a task and modify the solution space and interaction design based on the frequency and success of previous attempts.

- Provide multiple pathways to achieving a task - consumers should be able to choose their own pathway through to customize a product. "For novice consumers, encouraging a feeling of control may mean allowing little room for error. For more experienced consumers, control may mean the ability to gather and arrange their data and information in the way they want" [28].

- Provide assortment matching, i.e. automatically recommend configurations for consumers by matching their needs with characteristics of existing solution spaces [71].

\section{CONCLUSIONS}

In this article we have provided an overview of existing studies in MC toolkit design. Based on this overview, we have proposed an evaluation model, particularly focusing on the assessment of online 3D toolkit design from four aspects: solution space, interaction design, enabling technologies and individual differences. This study helps us understand the current state of MC research especially in terms of toolkit design in academia. Through the review, we have found that despite the number of studies on toolkit design, there is currently little research specially focusing on 3D toolkit design. However, 3D toolkit design is a special area which is quite different from 2D toolkit design in terms of the visual representation of products and the way consumers interact with the toolkits. Therefore, 3D toolkits bring different experiences to consumers when compared to 2D toolkits. On one hand, they have the potential to create a more realistic virtual environment for consumers. On the other hand, it is easy to cause cognitive difficulties in understanding 3D models. Besides, the design of 3D toolkits is closely related to technical development, especially the development of 3D modeling and web technologies. Therefore, devoting specific efforts to studying 3D toolkit design is necessary.

In addition, we found most current studies focus on establishing the theories of designing and implementing a mass customization system, but fail to consider whether or not the systems designed based on their theories can actually provide consumers with satisfying experience. This consideration leads to the next part of the article which is a heuristic evaluation of four different types of MC toolkits in current market by applying the evaluation model we proposed in this article. We expect to test the validity of the model through the evaluations and also identify the problems and shortcomings of existing 3D MC toolkit design.

\section{ACKNOWLEDGEMENT}

This work is funded by the European Commission Horizon 2020 - Marie Curie Individual Fellowship [grant number 661501]

\section{REFERENCES}

[1] Abdallah, A.; Fryazinov, O.; Adzhiev, V.; Pasko, A.: 3D Web-Based Shape Modelling: Building up an Adaptive Architecture, The Seventh International Conference on Advances in Computer-Human Interactions, 2014, 96-102.

[2] Adzhiev, V.; Cartwright, R.; Fausett, E.; Ossipov, A., Pasko, A.; Savchenko, V.: Hyperfun project: A framework for collaborative multidimensional f-rep modeling, Implicit Surfaces,Vol. 99, 1999, 59-69.

[3] Adzhiev, V.; Comninos, P.; Kazakov, M.; Pasko, A.: Functionally based augmented sculpting, Computer Animation and Virtual Worlds, vol. 16, No. 1, 2005, 25-39. https://doi.org/10.1002/cav.54

[4] Adzhiev, V.; Kartasheva, E.; Kunii, T.; Pasko, A.; Schmitt, B.: Hybrid cellular- functional modeling of heterogeneous objects, Journal of Computing and Information Science in Engineering, Transactions of the ASME, vol. 2, No. 4, 2002, 312-322. https://doi.org/10.1115/1.1559580 
[5] Allègre, R.; Galin, E.; Chaine, R.; Akkouche, S.: The hybridtree: Mixing skeletal implicit surfaces, triangle meshes, and point sets in a free-form modeling system, Graphical models, 68(1), 2006, 42-64. https://doi.org/10.1016/j.gmod.2005.09.001

[6] Bandura, A.: Self-efficacy: The exercise of control, New York, 1997.

[7] Batra, R.; Ahtola, O. T.: Measuring the hedonic and utilitarian sources of consumer attitudes, Marketing letters, 2(2), 1991, 159-170. https://doi.org/10.1007/BF00436035

[8] Berger, C.; Piller, F.: Customers as co-designers, MANUFACTURING ENGINEER- LONDON-, 82(4), 2003, 42-45. https://doi.org/10.1049/me:20030407

[9] Blake, B. F.; Neuendorf, K. A.; Valdiserri, C. M.: Tailoring new websites to appeal to those most likely to shop online, Technovation, 25(10), 2005, 1205-1214. https://doi.org/10.1016/j.technovation.2004.03.009

[10] Bloch, P. H.: Seeking the ideal form: product design and consumer response, The Journal of Marketing, 1995, 16-29. https://doi.org/10.2307/1252116

[11] Boese, E. S.: An introduction to programming with Java applets, Jones \& Bartlett Publishers, 2009.

[12] Bowyer, A.; Eisenthal, D.; Pidcock, D.; Wise, K.: Configurations, constraints, and CSG, International Journal of Shape Modeling, 6(02), 2000. 131-143. https://doi.org/10.1142/S0218654300000107

[13] Chen, J.; Shapiro, V.; Suresh, K.; Tsukanov, I.: Shape optimization with topological changes and parametric control, International journal for numerical methods in engineering, 71(3), 2007, 313346. https://doi.org/10.1002/nme.1943

[14] Chitturi, R.; Raghunathan, R.; Mahajan, V.: Delight by design: The role of hedonic versus utilitarian benefits, Journal of Marketing, 72(3), 2008, 48-63. https://doi.org/10.1509/jmkg.72.3.48

[15] Daugherty, T.; Li, H.; Biocca, F.: Consumer learning and 3-D ecommerce: The effects of sequential exposure of a virtual experience relative to indirect and direct product experience on product knowledge, brand attitude and purchase intention, Unpublished Dissertation, Michigan State University, East Lansing, MI, 2001.

[16] Davis, S. M.: Future perfect, Basic Books, 1987. https://doi.org/10.1007/978-1-349-11255-5_2

[17] Davis, S. M.: From "future perfect": Mass customizing, Planning review, 17(2), 1989, 16-21. https://doi.org/10.1108/eb054249

[18] Dhar, R.; Wertenbroch, K.: Consumer choice between hedonic and utilitarian goods, Journal of marketing research, 37(1), 2000, 60-71. https://doi.org/10.1509/jmkr.37.1.60.18718

[19] Dykstra, D.J.: A Comparison of Heuristic Evaluation and Usability Testing: The Efficacy of a Domain-Specific Heuristic Checklist, Ph.D dissertation, Department of Industrial Engineering, Texas A\&M University, 1993.

[20] Farr, J. L.; West, M. A.: Innovation and creativity at work: Psychological and organizational strategies, John Wiley \& Sons, 1990. https://doi.org/10.2307/2393481

[21] Fogliatto, F. S.; da Silveira, G. J.; Borenstein, D.: The mass customization decade: An updated review of the literature, International Journal of Production Economics, 138(1), 2012, 14-25. https://doi.org/10.1016/j.ijpe.2012.03.002

[22] Franke, N.; Hader, C.: Mass or Only "Niche Customization"? Why We Should Interpret Configuration Toolkits as Learning Instruments, Journal of Product Innovation Management, 31(6), 2014, 1214-1234. https://doi.org/10.1111/jpim.12137

[23] Franke, N.; Piller, F. T.: Key research issues in user interaction with user toolkits in a mass customisation system, International Journal of Technology Management, 26(5-6), 2003, 578-599. https://doi.org/10.1504/IJTM.2003.003424

[24] Franke, N.; Piller, F.: Toolkits of User Innovation and Design: an Exploration of User Interaction and Value Creation in the Watch Market, Proceedings of the 2nd Interdisciplinary World Congress on Mass Customization and Personalization, 2003.

[25] Franke, N.; Shah, S.: How communities support innovative activities: an exploration of assistance and sharing among end-users, Research policy, 32(1), 2003, 157-178. https://doi.org/10.1016/S0048-7333(02)00006-9

[26] Füller, J.; Matzler, K.; Hutter, K.; Hautz, J.: Consumers' creative talent: Which characteristics qualify consumers for open innovation projects? An exploration of asymmetrical effects, Creativity and Innovation Management, 21(3), 2012, 247-262. https://doi.org/10.1111/j.14678691.2012.00650.x 
[27] Gandhi, A.; Magar, C.; Roberts, R.: How technology can drive the next wave of mass customization, Business Technology Office, 2014, 1-8.

[28] Gerber, E. M.; Martin, C. K.: Supporting creativity within web-based self- services, International Journal of Design, 6(1), 2012, 85-100.

[29] Harston, H. R.: Human-computer interaction: Interdisciplinary roots and trends, Journal of Systems and Software, 43, 1998, 103-118. https://doi.org/10.1016/S0164-1212(98)10026-2

[30] Havemann, S.; Fellner, D. W.: Towards a new shape description paradigm using the Generative Modeling Language, Lecture Notes in Computer Science, Springer Berlin Heidelberg, 2011, 200214. https://doi.org/10.1007/978-3-642-19391-0_15

[31] Hermans, G.: A model for evaluating the solution space of mass customization toolkits, International Journal of Industrial Engineering and Management, 3(4), 2012, 205- 214.

[32] Hermans, G.: Identifying user-as-designer behaviors when designing by using toolkits, Proceedings of the 10th European Academy of Design Conference, Gothenburg, Sweden: University of Gothenburg, 2013.

[33] Hermans, G.; Stolterman, E.: Exploring parametric design: Consumer customization of an everyday object, Design Research Society 2012 Bangkok, Chulalongkorn University, 2012, 707717.

[34] von Hippel, E.: User toolkits for innovation, Journal of product innovation management, 18(4), 2001, 247-257. https://doi.org/10.1111/1540-5885.1840247

[35] Hoffmann, C. M.: Geometric and Solid Modeling, Morgan Kaufmann Pub, 1998.

[36] Hoffmann, C. M.; Joan-Arinyo, R.: Parametric Modeling, Handbook of Computer Aided Geometric Design, 2002, 519-541.

[37] Holbrook, M. B.: Some preliminary notes on research in consumer esthetics, Advances in consumer research, 7(1), 1980, 104-108.

[38] Holbrook, M. B.; Hirschman, E. C.: The experiential aspects of consumption: Consumer fantasies, feelings, and fun, Journal of consumer research, 9(2), 1982, 132-140. https://doi.org/10.1086/208906

[39] Huang, Z.; Benyoucef, M.: From e-commerce to social commerce: A close look at design features, Electronic Commerce Research and Applications, 12(4), 2013, 246-259. https://doi.org/10.1016/j.elerap.2012.12.003

[40] Huffman, C.; Kahn, B. E.: Variety for sale: mass customization or mass confusion?, Journal of retailing, 74(4), 1998, 491-513. https://doi.org/10.1016/S0022-4359(99)80105-5

[41] Hunt, D. M.; Radford, S. K.; Evans, K. R.: Individual differences in consumer value for mass customized products, Journal of Consumer Behaviour, 12(4), 2013, 327-336. https://doi.org/10.1002/cb.1428

[42] Jeffries, R.; Miller, J. R.; Wharton, C.; Uyeda, K.: User interface evaluation in the real world: a comparison of four techniques, Proceedings of the SIGCHI conference on Human factors in computing systems, ACM, 1991, 119-124. https://doi.org/10.1145/108844.108862

[43] Jenkins, H.: Confronting the challenges of participatory culture: Media education for the 21st century, MIT Press, 2009.

[44] Kaplan, A. M.; Haenlein, M.: Toward a parsimonious definition of traditional and electronic mass customization, Journal of product innovation management, 23(2), 2006, 168-182. https://doi.org/10.1111/j.1540-5885.2006.00190.x

[45] Karat, C. M.; Campbell, R.; Fiegel, T.: Comparison of empirical testing and walkthrough methods in user interface evaluation, Proceedings of the SIGCHI conference on Human factors in computing systems, ACM, 1992, 397-404. https://doi.org/10.1145/142750.142873

[46] Khalid, H. M.: Can customer needs express affective design, Proceeding of Affective Human Factors Design, 2001, 190-198.

[47] Khalid, H. M.; Helander, M. G.: Web-based do-it-yourself product design, The customer centric enterprise, Springer Berlin Heidelberg, 2003, 247-266. https://doi.org/10.1007/978-3-642-554605_13

[48] Khalid, H. M.; Oon, Y. B.: Usability of Configuration Systems in Design by Customer Web Sites, Proceedings of the Human Factors and Ergonomics Society Annual Meeting, SAGE Publications, 2003, 811-815. https://doi.org/10.1177/154193120304700505 
[49] Kripac, J.: A mechanism for persistently naming topological entities in history-based parametric solid models, Proceedings of the third ACM symposium on Solid modeling and applications, ACM, 1995, 21-30. https://doi.org/10.1016/S0010-4485(96)00040-1

[50] Lin, C. H.; Hsu, Y. L.; Sun, T. H.: The Application of 3D Interactive Media on Mass Customization Design of Hardwood Furniture, Proceedings of International Conference on Planning and Design, Taiwan, 2003.

[51] Lüthje, C.: Characteristics of innovating users in a consumer goods field: An empirical study of sport-related product consumers, Technovation, 24(9), 2004, 683-695. https://doi.org/10.15480/882.97

[52] Maes, P.: Agents that reduce work and information overload, Communications of the ACM, 37(7), 1994, 30-40. https://doi.org/10.1145/176789.176792

[53] Matzler, K.; Stieger, D.; Füller, J.: Consumer confusion in internet-based mass customization: Testing a network of antecedents and consequences, Journal of Consumer Policy, 34(2), 2011, 231-247. https://doi.org/10.1007/s10603-011-9157-6

[54] Miller, G. A.: The magical number seven, plus or minus two: some limits on our capacity for processing information, Psychological review, 63(2), 1956, 81. https://doi.org/10.1037/h0043158

[55] Mitchell, V. W.; Walsh, G.; Yami, M.: Towards a Conceptual Model of Consumer Confusion, Advances in Consumer Research, 32(1), 2005, 143-150.

[56] Nelson, H. G.; Stolterman, E.: The design way: Intentional change in an unpredictable world: Foundations and fundamentals of design competence, Educational Technology, 2003. https://doi.org/10.1016/j.ejor.2005.07.013

[57] Nielsen, J.: Usability inspection methods, Proceedings of Conference companion on Human factors in computing systems, ACM, 1994, 413-414. https://doi.org/10.1145/259963.260531

[58] Ng, Y. M.: Customizable 3D virtual objects: a breakthrough in electronic catalogs in Internet business, MPhil thesis, The Hong Kong University of Science and Technology, Hong Kong, 2000.

[59] Nichols, S.; Haldane, C.; Wilson, J. R.: Measurement of presence and its consequences in virtual environments, International Journal of Human-Computer Studies, 52(3), 2000, 471-491. https://doi.org/10.1006/ijhc.1999.0343

[60] Noble, C. H.; Kumar, M.: Using product design strategically to create deeper consumer connections, Business Horizons, 51(5), 2008, 441-450. https://doi.org/10.1016/j.bushor.2008.03.006

[61] Parisi, T.: Programming 3D Applications with HTML5 and WebGL: 3D Animation and Visualization for Web Pages, O'Reilly Media, Inc, 2014.

[62] Pasko A.; Adzhiev V.; Sourin A.; Savchenko V.: Function representation in geometric modeling: concepts, implementation and applications, The Visual Computer, 11(8), 1995, 429-446. https://doi.org/10.1007/BF02464333

[63] Pasko, A.; Adzhiev, V.: Function-based shape modeling: mathematical framework and specialized language, Lecture Notes in Artificial Intelligence, Springer Berlin Heidelberg, 2004, 132-160. https://doi.org/10.1007/978-3-540-24616-9_9

[64] Pasko, A.; Adzhiev, V.; Comninos, P.: Heterogeneous objects modelling and applications: collection of papers on foundations and practice, Lecture Notes in Computer Science, vol. 4889, Springer Berlin, 2008. https://doi.org/10.1007/978-3-540-68443-5

[65] Piller, F.; Schubert, P.; Koch, M.; Möslein, K.: Overcoming mass confusion: collaborative customer co- design in online communities, Journal of Computer-Mediated Communication, 10(4), 2005. https://doi.org/10.1111/j.1083-6101.2005.tb00271.x

[66] Pine, B. J.: Mass Customization: The New Frontier in Business Competition, Harvard Business Press, 1993. https://doi.org/10.5465/AMR.1994.9412271820

[67] Pinelle, D.; Wong, N.; Stach, T.; Heuristic evaluation for games: usability principles for video game design, Proceedings of the SIGCHI Conference on Human Factors in Computing Systems, ACM, 2008, 1453-1462. https://doi.org/10.1145/1357054.1357282

[68] Randall, T.; Terwiesch, C.; Ulrich, K. T.: Research note-user design of customized products, Marketing Science, 26(2), 2007, 268-280. https://doi.org/ 10.1287/mksc.1050.0116

[69] Requicha, A. G.: Representations for rigid solids: Theory, methods, and systems, ACM Computing Surveys (CSUR), 12(4), 1980, 437-464. https://doi.org/10.1145/356827.356833 
[70] Requicha, A. A.; Voelcker, H. B.: Solid modeling: a historical summary and contemporary assessment, Computer Graphics and Applications, IEEE, 2(2), 1982, 9-24. https://doi.org/10.1109/MCG.1982.1674149

[71] Salvador, F.; De Holan, P. M.; Piller, F.: Cracking the code of mass customization, MIT Sloan Management Review, 50(3), 2009, 71-78.

[72] Schnurr, B.; Scholl-Grissemann, U.: Beauty or function? How different mass customization toolkits affect customers' process enjoyment, Journal of Consumer Behaviour, 14(5), 2015, 335343. https://doi.org/10.1002/cb.1524

[73] Shapiro, V.: Solid modeling, Handbook of computer aided geometric design, 20, 2002, 473- 518. https://doi.org/10.1016/B978-044451104-1/50021-6

[74] Shapiro, V.; Vossler, D. L.: What is a parametric family of solids?, Proceedings of the third ACM symposium on Solid modeling and applications, ACM, 1995, 43-54. https://doi.org/10.1145/218013.218029

[75] Shugrina, M.; Shamir, A.; Matusik, W.: Fab forms: customizable objects for fabrication with validity and geometry caching, ACM Transactions on Graphics (TOG), 34(4), 2015, 100. https://doi.org/10.1145/2766994

[76] Snyder, J. M.: Generative modeling for computer graphics and CAD, Academic press, 1992.

[77] Thau, D.: The Book of JavaScript: A Practical guide to interactive Web pages, No Starch Press, 2006.

[78] Totz, C.; Riemer, K.: The effect of interface quality on success-an integrative approach on mass customization design, Proceedings of the 1st World Congress on Mass Customization and Personalization, Hong-Kong, 2001.

[79] Tseng, M.M.; Jiao, J.: Mass Customization, in: Handbook of Industrial Engineering, Technology and Operation Management, Wiley, 2001. https://doi.org/10.1002/9780470172339.ch25

[80] Vidimče, K.; Wang, S. P.; Ragan-Kelley, J.; Matusik, W.: Openfab: A programmable pipeline for multi-material fabrication, ACM Transactions on Graphics (TOG), 32(4), 2013, 136. https://doi.org/10.1145/2461912.2461993

[81] Vilbrandt, T.; Fryazinov, O.; Stamm, C.; Pasko, A.: A web oriented function-based volume modeling framework, Technical Report TR-NCCA-2008-02, Bournemouth University, 2008.

[82] Von Neumann, J.: Can we survive technology? Time, Incorporated, 1955.

[83] Walcher, D.; Piller, F. T.: The customization 500: an international benchmark study on mass customization and personalization in consumer e-commerce, ICON Group International, 2012.

[84] West, M. A.; Farr, J. L.: Innovation and creativity at work: psychological and organizational strategies, Wiley, 1990. https://doi.org/10.2307/2393481

[85] Westland, J. C.; Au, G.: A comparison of shopping experiences across three competing digital retailing interfaces, International Journal of Electronic Commerce, 2(2), 1997, 57-69. https://doi.org/10.1080/10864415.1997.11518308

[86] Wikström, S.: Value creation by company-consumer interaction, Journal of Marketing Management, 12(5), 1996, 359-374. 